\title{
A escolarização e as práticas sociais de leitura e escrita: a análise dos educandos adultos da Escola Básica
}

\author{
Maria da Conceição R. Fonseca \\ Universidade Estadual de Campinas, Brasil \\ Fernanda M. Simões \\ Universidade Federal de Minas Gerais, Brasil
}

\begin{abstract}
Resumo
Este artigo traz reflexões desencadeadas a partir de uma investigação, realizada no Projeto de Ensino Fundamental de Jovens e Adultos da Universidade Federal de Minas Gerais (Brasil), sobre os modos como pessoas adultas em processo de escolarização básica analisam suas práticas de leitura e escrita, percebem as experiências de letramento vivenciadas na instituição escolar e avaliam seus possíveis impactos naquelas práticas. A análise de quatro entrevistas semiestruturadas com alunos da Educação de Jovens e Adultos sugere que os sujeitos consideram a diversidade de suas práticas de leitura e escrita e reconhecem, mas relativizam, o papel da escola na promoção de práticas letradas de uso social. Os entrevistados identificam a ampliação e o refinamento de suas práticas de leitura e escrita, desencadeados pelas demandas e pelas oportunidades da vivência escolar. Apontam, porém, para uma certa independência de suas práticas de letramento cotidianas em relação às da escola, independência esta conquistada em decorrência da experiência escolar ou preservada apesar dela.
\end{abstract}

Palavras-chave

Educação de jovens e adultos; Letramento; Sentido e significado

\section{Apresentação}

Este artigo traz reflexões desencadeadas a partir de uma investigação sobre as percepções de pessoas adultas em processo de escolarização 
básica relativamente às suas práticas de leitura e escrita. Procuramos analisar os modos como homens e mulheres com pouca escolarização compreendem suas práticas de leitura e escrita, identificar as experiências de letramento vivenciadas na instituição escolar e discutir seus possíveis impactos nessas práticas. A pesquisa foi realizada no Projeto de Ensino Fundamental de Jovens e Adultos $-2^{\circ}$ Segmento (PROEF 2) da Universidade Federal de Minas Gerais. Foram analisadas quatro entrevistas semiestruturadas com sujeitos educandos da Educação de Jovens e Adultos (EJA) que, no momento da investigação, cursavam o segundo ano de um ciclo de escolarização correspondente ao período de $5^{\mathrm{a}}$ a $8^{\mathrm{a}}$ série do Ensino Fundamental no Brasil ( $2^{\circ}$ e $3^{\circ}$ Ciclos do Ensino Básico em Portugal). As análises das entrevistas, que estão em diálogo com a produção teórica nas áreas do Letramento e da Educação de Jovens e Adultos, sugerem que esses estudantes consideram a diversidade de suas práticas de leitura e escrita e relativizam a representação da escola como a mais importante instituição responsável pela promoção de práticas letradas. Ao mesmo tempo, mostram que as práticas de letramento escolares são por eles avaliadas positivamente, à medida que propiciam o diálogo com as práticas sociais de letramento que vivenciam, as quais estão em permanente movimento de construção/reconstrução.

\section{Introdução}

O foco de reflexão que apresentamos neste trabalho são as práticas de letramento de pessoas adultas em processo de escolarização. Quando nos dispomos a investigar práticas de letramento, estamos interessadas em compreender não só "o que as pessoas fazem com as habilidades de leitura e escrita em um contexto específico", mas também "como estas habilidades se relacionam com as necessidades, valores e práticas sociais" (Soares, 2004: 72). A todos os educadores, e de modo especial àqueles que atuam na Educação de Jovens e Adultos, consideramos ser essencial conhecer os usos que os sujeitos fazem da escrita, como acontecem esses usos e os valores e noções que Ihes estão associados (Vóvio \& Sousa, 2005). Ao mesmo tempo, é de fundamental importância refletir sobre as relações entre as práticas sociais de leitura e escrita que os educandos vivenciam em diversas situações cotidianas e aquelas relacionadas ao letramento escolar ${ }^{1}$. 
Ribeiro (1999) e Soares (2003) apontam que, apesar de pesquisas sobre alfabetismo funcional das populações, como a do $\operatorname{INAF}^{2}$ (2003), indicarem uma decisiva importância da escola na constituição de práticas letradas, essa é uma hipótese que requer cuidados em sua abordagem e demanda que outros estudos sejam realizados, a fim de se compreenderem "as conseqüências da escolarização sobre os usos sociais da leitura e da escrita" (Soares, 2003: 111) e de se contemplar a complexidade de relações que envolvem esses usos. Com efeito, Ribeiro (1999a), ao estudar a relação entre práticas escolares e a promoção do letramento na Educação de Jovens e Adultos, percebe que os alunos de programas que viabilizam variadas práticas sociais de leitura e escrita, como a frequência à biblioteca e o uso do computador, leem mais livros fora da escola. Por outro lado, Silva (2003), ao investigar a formação de leitores adultos com escolarização extemporânea, concluirá que, ao lado da escola, a família, tanto a de origem, quanto a atual, desempenha um papel preponderante neste sentido.

Com base nessas reflexões e em diálogo com elas, este estudo buscou investigar, por meio de entrevistas com educandos de um projeto de extensão universitária para adultos que não concluíram o Ensino Fundamental, o PROEF $2^{3}$, os modos como esses sujeitos compreendem suas práticas de leitura e escrita e significam o papel da escola nesse processo.

Um dos critérios para escolha do PROEF 2 como campo de pesquisa foi o fato de sua proposta pedagógica explicitar sua intenção educativa de possibilitar aos educandos a apropriação de práticas sociais de leitura e escrita, visando qualificar sua participação na cultura letrada de forma crítica e autônoma ${ }^{4}$. Além disso, a opção por entrevistar sujeitos que cursavam o final da escolarização fundamental - que tivessem pelo menos dois anos de retorno à escola - teve por objetivo propiciar reflexões sobre as relações entre letramento escolar e letramento social na Educação de Jovens e Adultos. Os sujeitos entrevistados atenderam a um convite da pesquisadora, feito na sala de aula, ocasião em que foram explicados os propósitos da investigação. Realizamos entrevistas com seis sujeitos. Neste artigo, analisamos o material produzido a partir de quatro dessas entrevistas.

As análises aqui apresentadas são oriundas dos seguintes questionamentos: Que práticas sociais de leitura e escrita esses sujeitos 
vivenciaram antes de retomar os estudos? Quais os motivos ou propósitos do uso que faziam da leitura e da escrita? Como as utilizavam no cotidiano? Para esses alunos e essas alunas, qual o papel da escola na configuração de suas práticas sociais de leitura e escrita? Tendo participado de um projeto de EJA, consideram que sua inserção na instituição escolar influencia as maneiras de experimentarem a leitura e a escrita?

\section{A diversidade das práticas e agências de letramento}

Iniciamos esta análise salientando que as observações dos sujeitos entrevistados - Maridalva, José Pereira, Vitória e Valdeir ${ }^{5}$ - sobre suas práticas de letramento contradizem as concepções de leitura e de escrita que as consideram como uma atividade de natureza estritamente cognitiva, que mobilizaria umas tantas habilidades, independentemente das situações em que o sujeito é chamado a ler. Os depoimentos desses homens e dessas mulheres a respeito dos usos que fazem da leitura e da escrita evidenciam a criatividade e a variabilidade que caracterizam as práticas de letramento que, como atividade humana, constituem-se em torno de um conjunto de condições sociais (Galvão, 1999). Além disso, ao longo das entrevistas, foi possível perceber que os sujeitos da pesquisa, ao serem chamados para falarem de suas vivências, foram capazes de se distanciarem das experiências concretas com a leitura e a escrita e de se debruçarem sobre "o real como objeto de reflexão e não só de ação" (Oliveira, 1995: 158). A identificação desse movimento nos indica a necessidade de questionarmos a concepção simplista de que as pessoas pouco escolarizadas não seriam capazes de experimentar processos mais sofisticados de reflexão e metacognição. Aponta também para a importância de compreendermos, como o faz Oliveira (2001), a potencialidade reflexiva da vida adulta:

$\mathrm{O}$ adulto traz consigo uma história mais longa, de experiências, conhecimentos acumulados e reflexões sobre o mundo externo, sobre si mesmo e sobre outras pessoas; provavelmente, possui uma maior capacidade de reflexão sobre o conhecimento e os próprios processos de aprendizagem (Oliveira, 2001: 18).

Por outro lado, apesar de os alunos e as alunas da EJA apresentarem características comuns que os definem como um grupo - "a condição de 'não crianças', de excluídos da escola e de membros de determinados grupos culturais" (Oliveira, 2001: 16) -, é possível reconhecer as multiplicidades de 
suas histórias de vida e as singularidades que os distinguem, tendo em vista, por exemplo, o modo como significam suas vivências familiares, a educação que receberam e suas experiências no mundo do trabalho. Sendo assim, percebemos que cada sujeito da pesquisa descreve trajetórias próprias que definem experiências de leitura e escrita diferenciadas.

Foi com base na descrição que os sujeitos tecem dessas trajetórias e nas reflexões que fazem a respeito de suas práticas de letramento que pudemos depreender as categorias a partir das quais organizamos a análise que ora apresentamos.

\section{Leitura para instrução}

No estudo realizado, é problematizada a supremacia da instituição escolar como agência responsável pela promoção de usos da leitura e da escrita. $\mathrm{O}$ fato de os sujeitos entrevistados terem tido uma escolarização curta na infância e permanecerem muitos anos sem participar da educação formal não os impediu de participarem da cultura escrita. Apesar de reconhecerem o papel da escolarização atual em suas práticas de letramento, ressaltam a presença de outros fatores na promoção de tais práticas. Por meio da análise das entrevistas, foi possível perceber que esses sujeitos questionam a representação da escola como um "divisor de águas" na configuração de suas práticas de leitura e escrita. Assim, mesmo estando em processo de escolarização, relativizam o papel da instituição escolar na promoção do letramento e demonstram que a participação em experiências de leitura e escrita se diferencia de acordo com os diversos contextos que vivenciam.

Galvão (2001), ao analisar os processos de inserção de analfabetos e semianalfabetos no mundo da cultura escrita entre os anos de 1930-1950, também questiona a centralidade conferida à escola na aquisição e nos usos das habilidades de leitura e escrita. A autora ressalta outros fatores, como a experiência urbana e a leitura de cordel, responsáveis pela promoção de práticas letradas, auxiliando-nos a compreender a complexidade do fenômeno do letramento.

Da mesma forma, para Maridalva 6 e José Pereira 7 , a escola não tem exclusividade na promoção de práticas de leitura. Maridalva é enfática ao dizer que os estudos bíblicos - iniciados quatro anos antes de seu retorno à 
sala de aula - possibilitaram sua inserção em novas práticas sociais da leitura. José Pereira, por sua vez, ressalta a importância da sua inclusão no grupo Alcoólatras Anônimos para a realização de suas leituras:

Se não fosse isso [atividade na igreja], eu não teria tal acesso. Pela falta de obrigatoriedade, você acaba não fazendo. E lá eu tenho de aprender, eu tenho de fazer, eu tenho de saber pra ensinar, então isso nos obriga a buscar. Então me ajudou muito, me ajudou bastante, sabe? (Maridalva)

É, isso foi de 74 para cá... eu gosto... eu passei a ler, porque lá nessa reunião de alcoólicos anônimos eu passei a fazer palestras em hospitais e... então eu comecei a ler algum livros de medicina, que eu não podia falar coisa que eu não sabia acerca do alcoolismo. Então eu passei a me instruir sozinho para falar algo na vista da pessoa, falar em público, né... Então, sempre eu gostei de ler foi livros sobre jornalismo, ocultismo... (José Pereira).

Assim, esses sujeitos reconhecem o papel de outras agências na configuração das condições sociais de produção da leitura. Ao refletir sobre essa temática, Paiva (2001: 11) aponta a necessidade de a instituição escolar considerar "outros locais e situações em que as competências e aprendizagem da linguagem são desenvolvidas". Nessa mesma perspectiva, Ribeiro (1999) afirma a relevância de se investigarem essas agências e os modos como influem na construção de habilidades letradas, para ser possível compreender melhor as práticas de leitura e escrita dos alunos adultos pouco escolarizados.

Maridalva e José Pereira, diante da necessidade de ensinar na igreja e de proferir palestras sobre o alcoolismo, respectivamente, consideram o público para o qual vão falar e realizam as leituras que julgam necessárias para a configuração do diálogo. Nesses casos, o uso da leitura se mostrava essencial para qualificar a contribuição que traziam às interações de que passaram a participar, quando se inseriram nos grupos de Estudos Bíblicos ou de Alcoólicos Anônimos. A avaliação que esses sujeitos fazem sobre a influência de sua inserção nesses grupos para a apropriação de novas práticas de leitura corrobora a afirmação de Kalman (2004: 80) de que "os atos de ler e escrever se organizam em eventos socialmente organizados, nos quais a língua escrita é uma ferramenta necessária para alcançar propósitos comunicativos". 
Os propósitos comunicativos aventados por Maridalva e José Pereira demandam, entretanto, não apenas o domínio da forma de expressão, mas também a aprendizagem de conhecimentos relativos a um tema específico história bíblica e alcoolismo. Assim, as práticas de leitura a que se referem permitem refletir sobre as atitudes ${ }^{8}$ desses sujeitos em relação à aprendizagem. Eles evidenciam a busca de informações escritas como uma estratégia importante para o aprendizado de determinado assunto. Consideram, como destaca Ribeiro (1999), que o domínio da leitura é essencial à aprendizagem: segundo esses estudantes da EJA, para "aprender" e se "instruir" é preciso dedicar um momento específico à leitura de materiais escritos que contemplem o tema sobre o qual falarão.

\section{Ler para apropriar-se de um modo letrado de pensar o mundo}

Além do acesso à instrução, as práticas de leitura significam, para esses sujeitos, a apropriação de outros modos de compreender o outro especialmente o outro 'letrado'. De acordo com Oliveira (1995: 154), o próprio ato de lidar com o material escrito, o qual se encontra separado "do autor, do tempo e do local de sua criação", contribui para a construção de modos letrados de pensamento, caracterizados pelo pensar descontextualizado e independente das vivências individuais ${ }^{9}$. Nesse sentido, além da influência escolar, os sujeitos também identificam outras experiências de leitura que "favorecem a transcendência, pelo homem, das condições concretas de sua inserção no mundo e propiciam um modo letrado de funcionamento cognitivo" (Oliveira, 1995: 157):

Foi de 74 para cá que eu comecei a ler, mas assim sem mestre. Comecei a instruir sozinho assim, muito difícil.

\section{(E o que te impulsionou a ler em 74?)}

Primeiro, eu tinha um senhor que a gente era colega. A gente era colega de infância do filho dele. E eu já trabalhava com reformas de móveis. E ele então disse: 'José Pereira, você vai lidar com várias pessoas durante sua vida profissional. Você vai lidar com muitos profissionais e você vai ter que saber lidar com as pessoas. Não é só saber trabalhar'. E foi quando ele me orientou para mim poder estudar. Mas se eu não tivesse estudando, que eu deveria ler. Então eu passei a ler "Seleções" e pegava livros emprestados e lia jornais já assim... já velhos, de notícias velhas. E isso para mim foi... ele já é até falecido, 
mas para mim foi muito melhor que se ele tivesse me dado muito dinheiro. Foi uma grande coisa que ele fez, né, porque ele disse: 'Você vai ter dificuldade de lidar com as pessoas se você não ter instrução'. Então até hoje eu trabalho em várias repartições, do estado, em várias repartições públicas,... em vários lugares. E a gente tem que não é só saber trabalhar. A gente tem que saber é lidar com as pessoas, né... Fiz cursos de relações humanas. Gosto muito de ler área de relações humanas... (José Pereira).

Em meio à sua fala, percebe-se o valor social atribuído à leitura como uma prática que deveria suprir a falta da escolarização necessária para a manutenção de um bom relacionamento com seus clientes e colegas de trabalho. Apesar de José Pereira reconhecer a centralidade da instituição escolar em nossa sociedade - é lá que se aprende a 'lidar com as pessoas' -, o fato de não poder frequentá-la não o impede de encontrar outros meios capazes de possibilitar maior familiaridade com as práticas sociais valorizadas pela escola, que identificam um certo modo de compreender o mundo e que permitem lidar com aqueles que o compreendem desse modo.

Tal declaração nos permite refletir, igualmente, sobre atitudes relacionadas à expressão da subjetividade. Ribeiro (1999: 62) estabelece níveis de alfabetismo, que "correspondem à capacidade de resolver tarefas [que envolvem leitura e escrita] com diferentes graus de complexidade". $\mathrm{Na}$ pesquisa da autora, tais níveis são cotejados com "as exigências colocadas pela vida diária e pelo trabalho em diferentes segmentos do mercado de empregos" (1999: 63). Esse estudo aponta que atitudes de expressão da subjetividade delineam as práticas de letramento no grupo de sujeitos classificados como de grau médio-baixo de alfabetismo; porém, são mais marcantes nas práticas do grupo de grau médio-alto ${ }^{10}$. Tais atitudes referemse à valorização da leitura para ampliação dos horizontes culturais e da capacidade comunicativa dos sujeitos. É nesse sentido que interpretamos o depoimento de José Pereira, reconhecendo o destaque que ele confere à leitura para o "desenvolvimento da linguagem oral, de sua capacidade de interagir com a diversidade de pessoas com quem se relaciona no contexto profissional" (Ribeiro, 1999: 144).

\section{Leitura e escrita para expressão da subjetividade}

As experiências de Vitória e Valdeir ${ }^{11}$ com a leitura e a escrita foram diferentes. Suas práticas estão mais diretamente associadas ao prazer e ao 
gosto. Enquanto Vitória afirma a predileção por romances, Valdeir enfatiza que, desde pequeno, gosta de escrever poemas. Ademais, diz apreciar a leitura de poesias em detrimento de outros gêneros de leitura, como a Bíblia e livros escritos em prosa. Ao serem perguntados sobre o que os levou a desenvolver tais práticas de letramento, esses sujeitos declaram razões ligadas à expressão da subjetividade ${ }^{12}$ e não associadas a finalidades utilitárias imediatas:

Lia por curiosidade mesmo, interesse, não era nada, igual... Um livro que eu gostei muito: 'O grande Q'. Eu tenho ele aqui, eu já li ele duas vezes. Eu lembro um livro que eu li há muito tempo atrás: 'O pequeno Lorde'. Eu gostava de ler assim, por... Eu gostava não, eu gosto (Vitória).

Eu acho que eu nasci gostando, viu... não lembro quando foi que eu descobri não (...) Na verdade, eu acredito que o porquê que eu que escrevo, eu acho que... às vezes, eu quero falar uma coisa pra você e eu não tenho coragem de falar pra você. $E$ às vezes eu não tenho coragem de falar pra você e às vezes quando eu vou falar, se caso eu resolver falar, quando eu vou falar, eu falo outras coisas e eu esqueço aquilo. E eu escrevendo, vai ficar registrado. Aí eu tenho mais coragem de expressar no papel. Aí, no papel, eu me abro mais. Parece que eu estou falando com a pessoa que eu confio muito mesmo e me abro e conto tudo que tenho que contar no papel. E falando com a pessoa direto parece que você substitui palavras, substitui até o sentido da coisa e não fala o que deve ser falado, tipo uma falta de coragem de falar cara a cara. Mas não é a falta de coragem. Você acaba esquecendo e substituíndo aquilo que você ia falar (Valdeir).

Valdeir destaca vantagens do registro escrito sobre o oral, tais como a objetividade, a organização e o controle da produção - "quando eu vou falar, eu falo outras coisas e eu esqueço aquilo. E eu escrevendo, vai ficar registrado". Mas enfatiza também a abertura que a interlocução mediada por "contar no papel" possibilita à expressão da subjetividade, às vezes intimidada pelas pressões da comunicação oral.

O relato desse sujeito sobre o momento em que se dedicava à escrita de poesias confirma-nos, ainda, o caráter não-pragmático de sua prática: "Sempre à noite, de madrugada e quando está chovendo", demonstrando ter uma relação sinestésica com a escrita de poesia. Incorporam-se à prática dessa escrita os silêncios da noite, os ruídos da chuva, o frescor da madrugada... É nesse mesmo domínio, associado "a ações e relações orientadas para fins não-pragmáticos" (Ribeiro, 1999: 138), que Vitória inscreve suas práticas de leitura: 
Isso sempre fiz, leitura bíblica sempre fiz. Isso aí não tem dia nem hora não: me dá vontade, eu vou lá e leio. Porque, na verdade, nós, católicos, não temos muito o hábito de ler a Bíblia, mas eu, particularmente, eu gosto (Vitória).

\section{Leitura e escrita para comunicação}

Vitória também se refere à escrita de cartas como uma prática recorrente em sua juventude, até porque outras práticas de comunicação à distância Ihe eram vedadas: "Telefone, meu pai nunca gostava que usasse porque, naquela época então, era muito caro". A escrita de cartas, porém, é, de certa forma, abandonada quando Vitória deixa a cidade do interior em que morava e se muda para Belo Horizonte:

Agora já dei uma parada, né... não estou gostando muito mais não. Não é que eu não estou gostando; é que não sei... parece que... a gente fala muito no telefone. A gente fala muito no telefone e a gente acaba não escrevendo carta. Hoje em dia, eu escrevo muito... agora que você chegou, eu até ia estava escrevendo porque minha sobrinha me mandou uma mensagem pra mim e eu ia responder... no celular (Vitória).

Vitória, ao falar da mudança em sua prática de escrita, corrobora as reflexões de Kleiman (1995: 39), segundo a qual "as práticas de letramento mudam segundo o contexto". A variação da disponibilidade de mídias para comunicação terá, pois, influência direta nas práticas de leitura e escrita de Vitória: a comunicação oral ao telefone é preterida em relação à comunicação por cartas, que é, por sua vez, se não substituída, inibida pela comunicação escrita de mensagens pelo celular. Nesse sentido, reafirma-se o caráter social das práticas de letramento, em que as condições históricas e sociais engendram diferentes usos da leitura e da escrita que "não podem ser inferidos de uma essência da leitura mesma" (Galvão, 1999: 20).

\section{Práticas de leitura e escrita atualizadas no acompanhamento escolar aos filhos}

Uma outra prática de leitura e escrita, presente somente nos depoimentos de Maridalva e Vitória, relaciona-se ao acompanhamento dos filhos nos deveres escolares e em outras práticas de letramento promovidas pela escola. Em relação aos deveres escolares, Vitória declara que não só 
ensinava aos filhos, mas também ajudava as crianças da rua, por ser muito conhecida pela vizinhança. Sendo assim, afirma que "sempre estava ensinando e em prática". Já Maridalva conta:

O princípio dos meus filhos eu acompanhei tranquilamente, até eles conseguirem caminharem sozinhos na escola. Eles tinham prática de escrever em casa. Quando eles foram pra escola, eles já tinham uma boa coordenação motora. Aquilo que eles passavam pra mim no interior, eu não sei como que é hoje, o ensino voltado para criança como que é, mas no nosso tempo, no meu tempo, a gente, a nossa coordenação motora era feita com aquelas coisinhas assim...assim... sabe... (Maridalva).

É interessante observar que Maridalva busca possibilitar o contato dos filhos com a cultura escrita mesmo antes do ingresso na escola. Ela re-edita as preocupações com o desenvolvimento do controle motor como requisito para o aprendizado da escrita, o que reflete a concepção que traz sobre o papel da instrução escolar nesse aprendizado. O fato de só as mulheres se referirem a tais práticas, ainda que em uma amostra tão limitada, remete à questão de gênero aí envolvida, reafirmando o que as pesquisas de Lareau (apud Carvalho, 2004: 102) e tantas outras confirmam recorrentemente: "As mães de classe média e trabalhadora assumem os encargos educacionais cotidianos, enquanto os pais exercem apenas um papel simbólico no trato com as autoridades escolares".

As análises aqui tecidas apontam que, ao mesmo tempo em que os sujeitos entrevistados questionam a exclusividade da escola na promoção de práticas letradas, sugerindo que "é preciso levar em conta que as pessoas criam para si oportunidades relacionadas ao alfabetismo" (Ribeiro, 1999: 168), o conhecimento das práticas de leitura e escrita não-escolares e das habilidades nelas envolvidas é essencial à escola, a fim de que cumpra mais adequadamente o seu papel como uma importante agência de alfabetismo em nossa sociedade.

\section{Práticas de letramento na escola - o diálogo com outros usos sociais de leitura e escrita e as especificidades do letramento escolar}

Nesta seção, analisaremos os significados da experiência escolar de letramento - conjunto de "eventos e práticas de letramento planejados e 
instituídos, selecionados por critérios pedagógicos, com objetivos prédeterminados e visando à aprendizagem" (Soares, 2003: 107) - para os sujeitos entrevistados. Foi possível perceber que os educandos reconhecem as especificidades desses eventos e dessas práticas e os qualificam de acordo com suas concepções e vivências de leitura e escrita. Vitória, por exemplo, reflete a respeito das experiências escolares atuais de leitura e escrita, comparando-as com a sua escolarização na infância:

Eu pego um trabalho pra fazer, chego aqui eu peço a ele [o marido] para pegar na Internet pra mim. Se ele não encontra, eu vou procurar na biblioteca, lá não tem muita coisa, às vezes não encontro. Eu pergunto a alguma pessoa, peço meu menino, sabe, para eu poder saber o que eu vou falar na frente. Então eu até estou achando que muitas coisas a gente aprende mais assim, do que lendo, decorando, né. Eu acho interessante o jeito que eles estão ensinando agora. Não é do jeito que eu aprendi antes. O ensino antes era muita matéria. Inclusive, quando eu estudei em Abaeté, eles passavam setenta e tantas perguntas para você decorar e tirar cinco para fazer uma prova. Eu nunca fui boa nem em História, nem em Geografia, nem em Ciência, quando eu estudei lá. Nunca fui de estudar, assim estudar matéria assim não. Eu gosto de ler. Outras coisas (Vitória).

Nesse trecho, Vitória contrapõe a experiência vivenciada na escola durante a infância, em que a leitura escolar é concebida como uma prática mecânica, baseada na transmissão da "matéria" e na memorização de perguntas e respostas, à que vive atualmente, em que as práticas de leitura e escrita se encontram em um contexto significativo. A análise de seu depoimento indica que sua primeira vivência escolar se baseia na consideração da leitura de textos dissertativos como a forma quase exclusiva de acesso ao conhecimento, leitura esta realizada com a intenção de responder perguntas pré-definidas - cujas respostas deveriam ser decoradas para que houvesse a aprendizagem. Sua experiência atual, todavia, parece incorporar a ampliação de usos sociais de leitura e escrita pela diversificação de mídias e gêneros textuais à disposição na sociedade, inserindo-os nas situações de ensino e aprendizagem - pesquisa em Internet, biblioteca, opinião ou informação que se pergunta aos outros, apresentações orais dos alunos.

Assim também, Maridalva salienta que a escolarização anterior era "cheia de decoreba" e ressalta a importância de a escola propiciar o contato com materiais escritos presentes na vida social: 
A própria forma de ensinar aqui te leva a ler outras coisas, e a buscar também outras fontes. Então às vezes aqui eles dão algum trabalho e eles te pedem informações de duas fontes ou de três fontes. E então eles nos levam a buscar mais. Às vezes você tem que buscar no jornal, internet, revista, enfim, você acaba fazendo coisas diferentes, sem dúvida (Maridalva).

Maridalva e Vitória indicam que a escola, ao requerer trabalhos em que é demandada a pesquisa, propicia a ampliação do universo de práticas culturais. O sucesso que atribuem a essa metodologia de diversificação de "fontes" e práticas de leitura para a apropriação do conhecimento também é apontado por Oliveira (2001: 59) quando afirma que "ao enfrentar tarefas significativas de leitura e escrita, os sujeitos podem experimentar estratégias diversas e refletir sobre sua eficácia em cada situação". Dessa forma, tais práticas de escolarização se configuram como um importante fator de incentivo ao desenvolvimento de habilidades e práticas relacionadas ao letramento, na medida em que forjam o reconhecimento dessas práticas como estratégias e objetos de aprendizagem.

Na mesma direção, José Pereira destaca o papel das práticas de leitura e escrita diversificadas como suporte para produção de textos, escritos e orais:

\begin{abstract}
Atividades com cartazes e apresentação de trabalho é muito importante para a desinibição do aluno. Uma vez nós tivemos aqui em baixo na cantina. Então isso é muito importante. Estas atividades de teatro, qualquer tipo de apresentação que todos os alunos têm que participar é muito importante. Essa atividade do meio ambiente, por exemplo, envolveu leitura e escrita porque teve que ler, teve que falar, apresentar os trabalhos todos lá na frente. Cada um leu o texto lá da onde eles estivessem para poder... para os outros alunos entenderem. Isso também tem muito a ver com a desinibição, todas estas atividades (José Pereira).
\end{abstract}

Segundo suas declarações, a escola, ao criar oportunidades para o desenvolvimento de habilidades de produção de textos orais e escritos em diferentes gêneros - cartazes, enquetes, apresentação oral, leitura em voz alta -, atende suas expectativas em relação ao trabalho com a leitura e a escrita. Como já foi mencionado, uma das práticas de leitura de José Pereira fora da escola está ligada à comunicação - palestras, em hospitais, relacionadas ao alcoolismo -, em que lhe é demandado "instruir-se" sozinho para falar algo "na vista da pessoa". Assim, sua fala nos sugere que a prática escolar é qualificada como positiva por aproximar-se dos usos sociais da leitura e da escrita e dialogar com eles. 
O depoimento de Valdeir, por sua vez, reconhece e demanda o lugar privilegiado da escrita e da leitura no processo de ensino e aprendizagem escolar:

Eu acho que deixou e continua a deixar a desejar a Geografia. Eu acho que Geografia no termo da leitura está muito escasso, muito devagar, está precisando mais leitura, mais escrita no quadro". As palavras... a palavra escrita é um documento, ela fica para toda vida e a palavra só falada é como uma folha seca, o vento leva, o vento leva e depois fica vazio, não tem nem como você lembrar, você esquece... você vê ali picado falando isso... isso... isso... está escrito uma palavra ali, mas não tem o contexto da matéria (Valdeir).

Ao criticar a prática escolar, Valdeir nos incentiva a pensar na função social da escola de promover e possibilitar a sistematização do conhecimento por meio do registro escrito, da "escrita no quadro" daquilo que foi aprendido. Como afirma Oliveira (1995), especificamente na escola constrói-se uma relação com o mundo por meio da linguagem e, de forma especial, pela escrita: "A escola é, assim, um lugar social onde o contato com o sistema de escrita e com a ciência enquanto modalidade de conhecimento se dá de forma sistemática e intensa" (1995: 156). É também por meio da palavra escrita, da leitura de "documentos", daquilo que "fica para toda a vida" que a escola cumpre seu papel de possibilitar o acesso a conhecimentos acumulados historicamente. Valdeir chega ao requinte de solicitar o exercício de um certo gênero dissertativo que lhe permita, melhor que os apontamentos feitos pelo professor, anotando palavras-chaves como apoio do texto oral, reconstruir "o contexto da matéria". Ao explicitar essa demanda, Valdeir posiciona-se também em relação ao gênero que considera adequado ao tratamento dos conhecimentos escolares, nesse caso, da disciplina Geografia.

Além da preocupação com o tipo - e a aprendizagem - de gêneros "adequados" à abordagem escolar, os entrevistados demandarão também o aprendizado de técnicas específicas para a produção de textos "corretos". Ao longo de nosso diálogo, ressaltaram, por exemplo, a relevância do trabalho com a ortografia, a pontuação e a "escrita correta":

A pontuação, eu nunca fui muito boa em pontuação não. Então isso eu tenho aprendido muito aqui. Então com certeza o que eu não consegui antes, eu vou conseguir aqui agora (Maridalva).

É... tem que aprender mais a escrever corretamente, pontuação, isso aí a gente precisa muito ainda (Vitória). 
Apesar de reconhecerem a importância e a obrigação de a escola ensinar a 'escrever corretamente', não parece ser isso que motiva, em primeira instância, a avaliação da prática escolar de leitura e escrita como positiva. Para eles, o papel essencial da escola como agência de letramento é potencializado quando as propostas pedagógicas Ihes permitem engajar em práticas que focalizem não somente o treino de habilidades, mas também os variados usos sociais de leitura e escrita.

Com efeito, os alunos destacam o papel da escola na promoção de experiências de leitura inéditas ou pouco usuais em sua vida cotidiana, especialmente aquelas que Ihes proporcionam uma vivência estética e cultural, que assumem uma significação em si mesmas. Ao relatarem uma experiência significativa de leitura e escrita, referem-se ao trabalho desenvolvido na aula de Filosofia a respeito da dramatização oral da tragédia grega "Édipo Rei". Os alunos estudaram o texto, interpretaram-no, analisaram o contexto histórico em que foi produzido, organizaram e ensaiaram uma dramatização, confeccionaram máscaras e construíram o cenário teatral para leitura dramatizada da tragédia, a ser apresentada aos colegas da escola:

Tem um monte de coisa que gostei no projeto. Por exemplo, o Felipe [o professor] há poucos dias nos passou aquela tragédia grega do Édipo Rei. Então nós tivemos de ler, nós tivemos de reler porque depois nós fomos apresentar (Maridalva).

Eu gostei - do Édipo Rei - porque primeiro tinha muita coisa escrita, né. Segundo que nós trabalhamos aquele texto, né. Até que a gente desvendou, descobriu o mistério do Édipo lá, aquela coisa lá. E depois a gente trabalhou até apresentar este texto. Então a gente viveu este texto, esta história. Parece que a gente passou a viver aquilo na vida da gente, mesmo (Valdeir).

Oliveira (1995) alerta que a construção de atitudes favoráveis ao alfabetismo dependerá das oportunidades criadas para que jovens e adultos expressem sua subjetividade, interessem-se em buscar novas informações e aprendizagens que ampliem sua visão de mundo e possibilidades de ação. Valdeir e Maridalva conferem especial relevância ao trabalho com um texto com muitas características distintas dos textos com que, em geral, lidam: a temática aborda arquétipos inseridos no contexto da Grécia Antiga e fala da tragédia humana atemporal; o estilo lança mão de diálogos na segunda pessoa (pouco usual nesta região do Brasil, em que se utiliza principalmente 
o pronome "você" para se referir ao interlocutor e, portanto, o verbo na terceira pessoa) e mobiliza vocábulos que jamais tinham usado ou mesmo ouvido; e a estrutura transgride a linearidade temporal da narrativa, cujo enredo se constrói a partir de diferentes pontos de vista e de experiências da história. Os sujeitos, alunos e alunas da EJA, reconhecem, nessa atividade escolar, a oportunidade de ampliar seus horizontes, conhecer outros contextos culturais, "viver histórias" produzidas em outros tempos e espaços, "descobrir mistérios"...

\section{A construção de novas práticas de leitura}

Nas entrevistas analisadas, dois sujeitos explicitaram que a vivência de práticas de letramento escolares propiciou a possibilidade de participar de, ou construir novas práticas de leitura, mesmo fora do contexto escolar. Tanto Vitória como Valdeir reportam que, a partir das experiências de leitura e escrita escolares, passaram a ler, em sua vida cotidiana, textos escritos diferentes daqueles com os quais tinham costume, ou ler aqueles que já liam, mas com outras finalidades:

\section{(Mas os romances, até hoje?)}

Agora eu quase que não tenho tempo ainda não, porque hoje em dia eu caí um pouquinho na real. Estas leituras são um pouco inúteis. Então, assim, hoje em dia eu já gosto de ler coisas mais interessantes.

\section{(Como?)}

Tipo assim, alguma coisa que vai me ensinar um pouco de história, sabe, história em geral. Não é história, história do Brasil, essas coisas não. História da vida, história de tudo. E eu percebi de um tempo para cá, que esta leitura que eu lia era muito inútil. Mas eu adoro ler revistinha em quadrinho, inclusive eu tenho um monte. Época, Galileu, Globo Rural, Veja, tudo isso eu gosto de ler (Vitória).

Vitória, ao afirmar que atualmente gosta "de ler coisas mais interessantes", nos sugere a descoberta de outras finalidades para a leitura, associadas à ampliação de seu universo de preocupações. Se antes essa prática estava ligada mais ao lazer, agora também está associada à aprendizagem ${ }^{13}$, à leitura de "alguma coisa que vai me ensinar". O privilégio que as práticas de letramento escolar concedem à leitura como meio eficaz 
de ensino-aprendizagem vai ao encontro da análise feita por Vitória, sugerindo que, após a entrada na escola, avaliou as leituras que gostava de realizar como "inúteis", quando comparadas àquelas que se tornam, aos seus olhos, "mais interessantes", por possibilitar-Ihe aprender mais. Nesse sentido, caberia a observação de Soares (2003: 109) quanto à necessidade de aprofundarmos a reflexão sobre "até que ponto o letramento escolar, (...) ultrapassa as paredes da escola como conseqüência de seu prestígio social e cultural, impondo comportamentos escolares de letramento e marginalizando outras variedades de letramento". Por outro lado, ao apropriar-se de uma prática de leitura típica da escola - ler para aprender -, Vitória re-significa essa prática, advertindo que a mobiliza não para aprender apenas conteúdos escolares ("história do Brasil, essas coisas"): ela busca leituras que lhe permitam aprender "histórias da vida, histórias de tudo".

Além disso, embora a experiência escolar tenha proporcionado a ampliação das suas práticas de leitura, Vitória constrói uma trajetória de leitura e escrita, em que a escola é uma das instituições responsáveis pela promoção de práticas letradas, mas não a única:

Ultimamente, você acha que ocupa seu tempo pra ler mais com as coisas da escola?

Não, acho que está meio a meio ainda. Eu uso o Projeto quando eu tenho que fazer atividade da escola. Eu li 'Mundo de Sofia' não foi por causa do Projeto. Foi porque eu gostei, achei interessante. Como meu marido não tem muito tempo pra ler, então na verdade eu costumo ler os textos dele e fazer um resumo pra ele. Ele está fazendo Administração de Empresa. Então, assim, não é que ele não lê não, ele lê, fica até duas ou três horas da manhã. Mas quando é uma coisa assim que tem que ser rápida ou coisa assim, aí eu dou uma lida. Falo: é assim, assim. Porque até nós dois temos pouco tempo para estar juntos... Mas não são todos não, porque não é sempre que eu tenho tempo. Ele até deixa os textos e fala: na hora que você tiver tempo, você lê para mim, se não tiver... (Vitória).

Ao nos mostrar a amplitude de seu universo de leitura - "li 'Mundo de Sofia' não foi por causa do Projeto. (...) costumo ler os textos dele" (de Administração de Empresas) -, Vitória relativiza o peso da instituição escolar na determinação de práticas sociais de leitura. Reitera, igualmente, as diferenças entre a leitura escolar relacionada a obrigações - "eu tenho que fazer a atividade da escola" - e a realizada fora da escola, associada "à 
necessidade ou interesse pessoal, vivida e interpretada de forma natural, até mesmo espontânea" (Soares, 2003:106). Tal questão nos coloca a necessidade de a escola abrir possibilidades para a realização de leituras com diversas finalidades e, ao mesmo tempo, legitimar as, e dialogar com as, práticas que os alunos realizam fora dessa instituição e que não são típicas da mesma.

Essa tensão entre a ampliação e a restrição de práticas de leitura promovidas pela experiência escolar será recorrentemente pontuada nos depoimentos dessas alunas e desses alunos da EJA. Valdeir, que declarou escrever poesias desde a infância, afirma que só passou a ler livros após frequentar a escola:

(Você acha que com o fato de voltar a estudar, você passou a usar mais a leitura e a escrita ou não?)

Passei, principalmente a leitura, né. Para ler mais as matérias, né. E me incentivou mais, porque eu não gostava de ler de jeito nenhum. Me incentivou mais. Porque eu lia jornal só. Agora eu leio livros, né, de vez em quando eu leio um livro. Eu li um livro da escola aqui, tem três histórias neles. Uma de Michelangelo, a outra... eu esqueci quais são as outras duas. Mas esse livro é da literatura americana, bom pra caramba (Valdeir).

A esse sujeito, a vivência de práticas de letramento escolares despertou o gosto por textos escritos que até então não lhe agradavam, em especial "os livros", objeto que a escola legitima como fonte privilegiada de conhecimento, "lugar" onde se leem "as matérias" ou onde se encontra a "literatura". O depoimento de Valdeir sugere que, ainda que o jornal constitua um material de leitura mais acessível, a leitura de livros é, muitas vezes, uma possibilidade oferecida pela escola, o que reforça sua função social de propiciar aos educandos a construção de outras práticas de leitura e escrita, ampliando seu universo de práticas culturais. Por outro lado, José Pereira afirma que a entrada na escola o obrigou a diminuir as práticas de leitura e escrita que desenvolvia antes. Atualmente, só tem tempo de realizar as tarefas escolares.

\section{(Em que época o senhor leu este livro?)}

Foi antes de entrar no Projeto. Porque, depois que eu entrei aqui, não está dando tempo de ler livro nenhum. 
É muita coisa, você começa a ler um livro e deixa para ler um livro do Projeto para fazer um trabalho (José Pereira).

Sua fala nos permite perceber que, para jovens e adultos que enfrentam o desafio de conciliar trabalho e estudo, as práticas de leitura e escrita se vinculam à sua disponibilidade de tempo. A frequência às aulas, aliada ao trabalho, em sua maioria em horário integral, impedem, muitas vezes, que os alunos participem de práticas sociais de letramento em outros tempos e espaços. Desse modo, Maridalva afirma que, devido à falta de tempo, as suas leituras fora da escola estão mais voltadas para a literatura evangélica porque, segundo ela: "eu tenho a rotina da casa, da escola e do trabalho; hoje eu não tenho muito tempo, hoje se eu quisesse ler mais não teria tempo, sabe...".

Maridalva, todavia, apesar de não explicitar que a escola lhe propiciou a leitura de outros textos escritos, indica-nos que a qualidade dessa prática melhorou. Ao falar de suas dificuldades de leitura, ressalta que

... por exemplo, uma reportagem de jornal, eu acho que são questões que às vezes estão escritas, que eu não conheço. Eu não tenho entendimento dele, então não é tudo que eu leio que eu entendo (...). É... hoje eu acho que já até melhorou, né. Porque hoje a gente trabalha dentro de sala com estes assuntos. Dá uma esmiuçada em alguma coisa de política. Às vezes um colega comenta alguma coisa, o professor reforça, então a mente vai abrindo... (Maridalva).

É interessante analisar que Maridalva evidencia dificuldades relacionadas ao entendimento dos textos que lê. Por meio de sua fala, podemos perceber que sua principal preocupação não está vinculada a aspectos gramaticais da língua e, sim, ao uso qualificado do sistema de escrita nas diversas práticas sociais. Assim, ao explicitar que, por meio da vivência de práticas escolares, passou a entender mais de assuntos relacionados à política, sinaliza que o trabalho da escola com temáticas presentes na vida social propicia aos alunos a possibilidade de ter melhor interação com os diversos gêneros textuais presentes em nossa sociedade, que Ihes permitam aprender mais sobre a "história da vida, a história de tudo".

\section{Considerações finais}

Este estudo buscou refletir sobre os modos como jovens e adultos com pouca escolarização compreendem suas próprias práticas de leitura e escrita, 
o trabalho desenvolvido com o sistema de escrita na escola e o papel da experiência escolar em suas práticas de letramento. Ao longo da pesquisa, os sujeitos evidenciaram que, apesar de cumprir um papel importante na promoção de práticas letradas, a escolarização não representa o único meio de desenvolvê-las. Esses alunos e essas alunas da EJA parecem se dar conta de que o leitor não se faz apenas pelas leituras escolares ou da escola, mas "pelas oportunidades de inserções culturais que lhe permitem navegar em outros contextos, cujos sentidos aprende a produzir e atribuir no mosaico de linguagens e de relações intertextuais que se estabelecem" (Paiva, 2001: 11).

Outrossim, avaliam as práticas escolares embasados em suas concepções e trajetórias de leitura e escrita, relacionando-as tanto à experiência escolar que tiveram na infância, como aos usos da leitura e da escrita que realizam fora da escola. Para eles e elas, as práticas escolares não constituem um bem em si mesmo: são qualificadas de forma positiva à medida que não se mantêm indiferentes ao contexto social e dialogam com o mesmo.

Por fim, mostram que, apesar de a construção de outras práticas de letramento depender de uma série de fatores, o modo como a escola concebe a leitura e a escrita e a natureza das práticas que implementa são essenciais para a construção e a consolidação de diversas práticas letradas.

\section{Notas}

1 Letramento escolar é entendido como os eventos de leitura e escrita promovidos pela escola a fim de que os educandos se apropriem de práticas sociais de leitura e escrita. Esse conceito é melhor explicitado ao longo da análise realizada no artigo.

2 Indicador Nacional de Alfabetismo Funcional, construído com os dados de pesquisa realizada anualmente entre os anos de 2001 e 2005 e bianualmente, a partir de então, pelo Instituto Paulo Montenegro e Ação Educativa, com uma amostra de 2002 sujeitos entre 15 e 64 anos, representativa da população brasileira nessa faixa etária.

3 O PROEF 2 oferece aos funcionários da universidade e à comunidade externa uma experiência de escolarização com a duração de três anos correspondente ao período de $5^{\mathrm{a}}$ à $8^{\mathrm{a}}$ série do Ensino Fundamental, com certificação no processo. $\mathrm{O}$ projeto integra o Programa de Educação Básica de Jovens e Adultos da UFMG, ao qual também se vinculam o Projeto de Ensino Fundamental de Jovens e Adultos $1^{\circ}$ Segmento (PROEF I) e o Projeto de Ensino Médio e Profissional de Jovens e Adultos (PEMJA). Os professores são estudantes das licenciaturas da UFMG, 
sendo que um dos objetivos do projeto é também contribuir para formação de Educadores de Jovens e Adultos. Para maiores reflexões, ver Fonseca (2000).

4 Segundo o projeto pedagógico/2003 do PROEF II, o trabalho com a leitura e a escrita busca possibilitar aos sujeitos o uso de diversos gêneros textuais e a construção de habilidades necessárias para que ampliem suas práticas de leitura e escrita fora da escola.

5 Os sujeitos autorizaram a veiculação de seus nomes verdadeiros na divulgação dos resultados da pesquisa. Foram analisadas entrevistas de dois homens e duas mulheres. Tinham, à época, idade entre 37 e 56 anos, e todos nasceram no interior de Minas Gerais. Neste texto, cada sujeito se dá a conhecer à medida que fragmentos de seus depoimentos são analisados.

6 Maridalva tinha 43 anos quando da realização da pesquisa. Trabalhava como costureira na própria casa. Ficou 30 anos sem frequentar a escola, e a ela voltou porque, como afirma, sempre teve "o sonho de concluir os estudos".

7 José Pereira tinha 56 anos na época da realização da pesquisa, era divorciado e trabalhava com reforma de estofados. Por ter que trabalhar, interrompeu os estudos aos 10 anos de idade, depois de frequentar por poucos meses a escola.

8 O conceito de atitude foi usado por Ribeiro (1999) referindo-se "a um estado de prontidão organizado pela experiência, que exerce uma influência direta e dinâmica sobre as respostas de um indivíduo diante de determinados objetos e situações" ( $p$. 53). Diz respeito a expressões individuais de padrões culturais mais amplos.

9 Essa discussão é desenvolvida por Oliveira (1995) em um estudo que procura compreender as relações entre cultura e modos de pensamento, enfocando principalmente sujeitos pouco escolarizados que estão integrados nas sociedades modernas, marcadamente urbanizadas, escolarizadas e industrializadas.

10 O grau médio-alto de alfabetismo refere-se a pessoas em que, "apesar das habilidades de leitura e escrita se concentrarem no trabalho, são também mobilizadas em outras dimensões, particularmente no ambiente familiar, visando o lazer, a educação dos filhos e a atualização dos próprios conhecimentos" (Ribeiro, 1999: 135).

11 Vitória tinha 37 anos e era dona de casa. Valdeir tinha 40 anos e estava desempregado.

12 Na pesquisa de Ribeiro (1999), a expressão da subjetividade é um dos domínios atitudinais utilizados a fim de entender como sujeitos que vivem em São Paulo se posicionam diante da leitura e da escrita.

13 Na pesquisa de Ribeiro (1999), atitudes relacionadas à aprendizagem pertencem a um dos domínios atitudinais utilizados a fim de entender como sujeitos que vivem em São Paulo se posicionam diante da leitura e da escrita.

\section{Referências}

Carvalho, M. E. P. (2004). Escola como extensão da família ou família como extensão da escola? O dever de casa e as relações família escola. Revista Brasileira de Educação n 25, 94-104. 
Fonseca, M. C. F. R. et al. (2000). O significado de um projeto de extensão universitária na formação inicial de educadores de jovens e adultos. Anais da $23^{a}$ Reunião Anual da Anped. Caxambu-MG. CD-ROM.

Galvão, A. M. O. (1999). Práticas de leitura, impressos, letramentos: Uma introdução. In A. A. G. Batista \& A. M. O. Galvão (Org.), Leitura: Práticas, impressos, letramentos (pp. 11-45). Belo Horizonte: Autêntica.

Galvão, A. M. O. (2001). Processos de inserção de analfabetos e semi-analfabetos no mundo da cultura escrita (1930-1950). Revista Brasileira de Educação, nº16, 81-94.

Kalman, J. (2004). O acesso à cultura escrita: A participação social e a apropriação de conhecimentos em eventos de leitura e de escrita. In J. Paiva \& I. B. Oliveira (Org.), Educação de jovens e adultos (pp. 71-100). Rio de Janeiro: DP\&A.

Kleiman, A. (1995). Modelos de letramento e as práticas de alfabetização na escola. In A. Kleiman (Org.), Os significados do letramento: Uma perspectiva sobre a prática social da escrita. Campinas, SP: Mercado de Letras.

Oliveira, M. K. (1995). Letramento, cultura e modalidades de pensamento. In A. Kleiman (Org.), Os significados do letramento: Uma perspectiva sobre a prática social da escrita (pp. 147-160). Campinas, SP: Mercado de Letras.

Oliveira, M. K. (2001). Jovens e adultos como sujeitos de conhecimento e aprendizagem. In V. M. Ribeiro (Org.), Educação de Jovens e Adultos: Novos leitores, novas leituras (pp.15-43). Campinas, SP: Mercado de Letras: Associação de Leitura do Brasil (ALB) / São Paulo: Ação Educativa.

Paiva, J. (2001). Novos significados para as aprendizagens da leitura na Educação de Jovens e Adultos. Alfabetização e Cidadania - Revista de Educação de Jovens e Adultos, $\mathrm{n}^{\circ}$ 12, 9-18.

Ribeiro, V. M. (1999a). A formação de educadores e a constituição da Educação de Jovens e Adultos como campo pedagógico. Educação e Sociedade, $\mathrm{n}^{\circ} 69,184-$ 201.

Ribeiro, V. M. (1999b). Alfabetismo e atitudes: Pesquisa com jovens e adultos. Campinas, SP: Papirus.

Silva, L. (2003). Formação de leitores adultos com escolarização irregular ou extemporânea. Dissertação de Mestrado. Belo Horizonte: UFMG.

Soares, M. (2003). Letramento e escolarização. In V. M. Ribeiro (Org.), Letramento no Brasil: Reflexões a partir do INAF 2001 (pp. 89-113). São Paulo: Global.

Soares, M. (2004). Letramento: Um tema em três gêneros. Belo Horizonte: Autêntica.

Vóvio, C. L., \& Souza, A. L. S. (2005). Desafios metodológicos em pesquisas sobre letramento. In A. B. Kleiman \& M. L. M. Matencio (Org.), Letramento e formação do professor: Práticas discursivas, representações e construção do saber (pp. 41-64). Campinas, SP: Mercado de Letras. 
SCHOOLING AND THE SOCIAL PRACTICES OF READING AND WRITING: THE ANALYSIS OF ADULT LEARNERS FROM BASIC SCHOOL

\begin{abstract}
This article brings about reflections of a research carried out in the Project for the Youth and Adults in Elementary School from Federal University of Minas Gerais (Brazil). These reflections are on how adults, in the process of basic schooling, analyze their practices of reading and writing, understand their literacy experiences in school and evaluate the potential impacts on those practices. The analysis of four semi-structured interviews with students from Youth and Adults Education suggests that they consider the diversity of their reading and writing practice and recognize, although in a relativistic way, the role of schools in the promotion of literate practices of social use. The interviewees identify the expansion and the refining of their practices in reading and writing, triggered by demands and opportunities of the school experience. They point, however, to a certain independence from their everyday practices of literacy in relation to the school practices, independence which is a result of school experience or which is, in spite of it, preserved.
\end{abstract}

Keywords

Youth and adults education; Literacy; Sense and meaning

\title{
LA SCOLARISATION ET LES PRATIQUES SOCIALES DE LECTURE ET D'ÉCRITURE : ANALYSE DES ÉLÈVES ADULTES DE L'ÉCOLE FONDAMENTAL
}

\section{Résumé}

En s'appuyant sur une investigation accomplie dans Le Projet d'Enseignement Fondamental de Jeunes et d'Adultes de l'Université Fédérale de Minas Gerais (Brésil), cet article met en discussion les manières avec lesquelles personnes adultes, soumises à la scolarisation, aperçoivent les expériences de "littératie" vécues et apprécient les impactes possibles de ces pratiques. L'analyse de 
quatre entrevues semi-structurées avec des élèves de l'Éducation de Jeunes et d'Adultes suggère qu'ils considèrent la diversité de leurs pratiques de lecture et d'écriture et reconnaissent le rôle de l'école dans le développement des pratiques lettrées de l'usage social, bien que d'une manière relative. Tout en admettant que leurs pratiques de lecture et d'écriture sont amplifiées et raffinées par les appels et les opportunités de la vie scolaire, les élèves identifient une certaine indépendance des pratiques quotidiennes de "littératie" par rapport à celles de l'école, cette indépendance conquise par l'expérience ou préservée, malgré cette même expérience.

Mots-clé

"Littératie"; Éducation de jeunes et d'adultes; Sens et signification

Recebido em Maio, 2009

Aceite para publicação em Dezembro, 2010

Toda a correspondência relativa a este artigo deve ser enviada para: Fernanda Maurício Simões, Rua Conceição do Mato Dentro, 250, apto 1203 A, Bairro Ouro Preto, Cidade Belo Horizonte, Minas Gerais, CEP 31310-240, Brasil. 